\title{
Professional Practice
}

\section{The Effect of a Life Development Intervention on Sports Career Transition Adjustment}

\author{
David Lavallee \\ Loughborough University, UK
}

\begin{abstract}
The purpose of this investigation was to evaluate the effectiveness of a life development intervention on career transition adjustment in retired professional athletes. Intervention $(n=32)$ and control groups $(n=39)$ were recruited for this study, both of which contained recently retired male professional soccer players. Data were collected on measures of career termination adjustment and coping with transitions, and the intervention group also participated in a life development intervention package. Results revealed significant postintervention treatment group differences on career transition adjustment in favor of the life development intervention, while significant within-group differences on career transition adjustment over time were also achieved for the intervention group. Results are discussed in relation to the personal and developmental costs of pursuing performance excellence.
\end{abstract}

In recent years, there has been increasing attention within the field of sport psychology on the question of whether the pursuit of performance excellence in elite-level sport occurs at the expense of the development of personal excellence by virtue of the demands placed upon athletes during their sporting careers (Danish, Petitpas, \& Hale, 1995; Miller \& Kerr, 2002). While the field initially focused on performance excellence primarily through psychological skills training (Andersen, Van Raalte, \& Brewer, 2001), it has more recently also started to examine the personal and developmental costs of pursuing performance excellence (Miller \& Kerr, 2002). Life skills, the abilities for adaptive and positive behavior that enable individuals to deal effectively with the demands and challenges of everyday life (World Health Organization, 1996), have been an important concept in this examination.

Danish and colleagues (Danish, Petitpas, \& Hale, 1993; Danish et al., 1995) have advocated that sport psychology has the potential to enhance both performance and personal excellence through the fostering of life skills. Such skills, which

The author is with Loughborough University, School of Sport and Exercise Sciences, Loughborough, LE11 2QW, England. E-mail: d.e.lavallee@lboro.ac.uk. 
are believed to be of life-long value (World Health Organization, 1996), include performing under pressure, communicating effectively with others, setting and attaining goals, and accepting criticism and feedback as part of learning. There has recently been a dramatic increase in the development of life skills programs for athletes, particularly on college and university campuses (Miller \& Kerr, 2002). Interestingly, however, the research-base on the effects of striving for performance excellence in sport is lacking (Gould, 2002).

In a recent article, Miller and Kerr (2002) highlighted specific research developments on the transition out of elite sport and how the pursuit of excellence can lead to distressful reactions upon career termination. While this issue has generally received haphazard attention by sports administrators, coaches, and others responsible for the well-being of athletes in the past (Gordon, 1995), interest in the area has grown considerably in recent years among sport psychology researchers. In fact, over 270 references have recently been generated on the topic of career transitions in sport (Lavallee, Wylleman, \& Sinclair, 2000) compared to 20 references being identified by McPherson in 1980. An international special-interest group has been initiated by members of the European Federation of Sport Psychology (FEPSAC) during the last few years to exchange information on applied and investigative work in the area (Wylleman, Alferman, \& Lavallee, 2004), and this organization has also recently published position statements on Sports Career Termination and Sports Career Transitions (FEPSAC, 2004) as well as a monograph on career transitions in competitive sports (Wylleman, Lavallee, \& Alfermann, 1999).

Although one of the only inevitabilities in high-performance sport is that eventually every competitor will have to terminate her or his sporting career at the elite level, some individuals have been found to experience psychological difficulties when faced with their retirement (Taylor \& Ogilvie, 2001). A review of the extant research that has examined and documented adjustment difficulties associated with retirement from sport identified that $20 \%$ of the athletes required considerable psychological adjustment upon their career termination (Grove, Lavallee, Gordon, \& Harvey, 1998). Until recently, however, the testing of psychological interventions for retired athletes remained largely unstudied (Wylleman et al., 2004). Therefore, the purpose of the present investigation was to assess the efficacy of a life development intervention on career transition adjustment in recently retired professional athletes. The study of recently retired athletes provides an interesting context to examine the potential costs of pursuing performance excellence, as previous research has found the pursuit of excellence during an athlete's career to be associated with personal adjustment difficulties thereafter (Miller \& Kerr, 2002). It was expected that the life development intervention employed in this investigation would significantly assist athletes who experience career termination adjustment difficulties in coping with the challenges of making a successful career transition.

\section{Method}

\section{Participants}

Two groups were recruited for this study, both of which contained recently retired male professional soccer players that played for premiership teams in England and Scotland and were either on the first or reserve team. A total of 41 individuals were 
referred ( 39 self-referred and 2 referred) to the author for psychological support with regard to their career termination (i.e., the day they stopped playing professional soccer) between 2000 and 2003, and all were invited to participate in a life development intervention study. A total of 32 (all self-referred) of these 41 individuals agreed to participate in the study, and thus made up the intervention group (Mean age $=29.04 ; S D=3.92$ ). The second group, which served as the control group, consisted of individuals who were contacted upon their career termination between 2002 and 2003 and invited to participate in the study by completing a battery of questionnaires. The criterion for inclusion in the control group was that they did not receive any psychological interventions during the immediate 4-month period following their career termination, and this was assessed via interviews with the participants at the conclusion of the study. A total of 41 individuals were invited to participate in the control group, and 39 (Mean age $=28.21 ; S D=4.33$ ) agreed to participate. All participants gave consent to participate in the study.

\section{Measures}

Both groups of athletes were invited to complete the British Athletes Lifestyle Assessment Needs in Career and Education (BALANCE) Scale (Lavallee \& Wylleman, 1999) and Transition Coping Questionnaire (TQC; Schlossberg, 1993) within three weeks of their career termination ( $M=15.2$ days, $S D=2.8$ days), as well as the TQC for a second time four months after their career termination.

The BALANCE Scale (Lavallee \& Wylleman, 1999) has been developed to assess the quality of adjustment to sports career termination by examining the following 12 areas, all of which have been shown by researchers to moderate adjustment to sports career termination: perception of control over the cause for retirement (Lavallee, Grove, \& Gordon, 1997); identity as an athlete (Grove, Lavallee \& Gordon, 1997); social support (Webb, Nasco, Riley, \& Headrick, 1998); previous experience with transitions (Swain, 1991); continued involvement in sport-related activities following retirement from competition (Curtis \& Ennis, 1988); degree of occupational planning (Grove et al., 1997); identity foreclosure (Murphy, Petitpas, \& Brewer, 1996); socioeconomic status (Kleiber, Greendorfer, Blinde, \& Sandall, 1987); transferable skills (Sinclair \& Orlick, 1993); achievement of sport-related goals (Sinclair \& Orlick, 1993); provision of career transition support services (Gorely, Lavallee, Bruce, Teale, \& Lavallee, 2001); and having a new focus after retirement (Baillie \& Danish, 1992). Response choices are answered on 7-point Likert-type scales ranging from 1 (Strongly Agree) to 7 (Strongly Disagree), resulting in one total score for the scale (with higher scores reflecting an individual being more at-risk to experience adjustment difficulties). The scoring range is $12-84$. This instrument has previously been shown to accurately predict career termination difficulties among samples of athletes, with scores above 65 indicating considerable career termination adjustment difficulties (Lavallee \& Wylleman, 1999; Lavallee, Golby \& Lavallee, 2002). The present study yielded a Cronbach alpha coefficient of .91.

The TCQ (Schlossberg, 1993) contains 45 questions that asks respondents to rate themselves on 5-point Likert scales ranging from 1 (Very Ineffective) to 5 (Very Effective) and other multi-part questions in four areas: how they see the transition that they are currently facing (Situation Scale $=8$ questions; Range $=8-40$ ); the personal characteristics that they bring to the transition (Self Scale $=8$ multi-part questions; Range $=10-50$ ); what help they have from others (Support Scale $=4$ 
multi-part questions; Range $=15-75)$; and how they tend to cope with transitions generally (Coping Strategies Scale $=25$ questions; Range $=25-125$ ). Schlossberg and colleagues (Schlossberg, 1993; Schlossberg, Waters, \& Goodman, 1995) have offered the following three classifications for the TCQ subscales: Strong, Moderate, and Low; the ranges for each of these classifications are as follows: Situation (Strong = 30-40; Moderate $=19-29 ;$ Low $=8-18) ;$ Self $($ Strong $=38-50 ;$ Moderate $=24-37$; Low $=10-23)$; Support (Strong $=55-75 ;$ Moderate $=35-54 ;$ Low $=15-34)$; Coping Strategies $($ Strong $=93-125 ;$ Moderate $=59-92 ;$ Low $=25-58)$. Previous research has demonstrated strong validity and reliability for this questionnaire (Schlossberg et al., 1995), and the Cronbach alpha coefficients in the present study were found to be acceptable across the four subscales (Range $=.74-.88$ ).

\section{Intervention}

The intervention group participated in a life development intervention package based upon a psychoeducational-developmental model described by Danish et al. (1993, 1995). This method of intervention emphasizes continued growth and change and is characterized by the use of enhancement strategies when working with individuals before an event (e.g., retirement) occurs, supportive strategies when working with individuals during an event, and counseling strategies when working with individuals after an event occurs. The intervention employed in this study utilized both supportive and counseling strategies and featured the following specific components: an initial assessment of life events, helping individuals to transfer skills from one domain to another, and teaching skills to help cope with future events.

It is essential in a life development intervention for the practitioner to make an initial assessment of life events (Danish et al., 1995). In this study, the assessment of life events was accomplished by inviting the participants to complete the Myers-Briggs Type Indicator (MBTI; Myers \& McCaulley, 1985) and Strong Interest Inventory (SII; Consulting Psychologists Press, 1985) during an intake session, as well as the associated counseling session based on the reports during the second session of the intervention. Whereas the MBTI (consisting of 93 items) provides an individual's personality type, which can be applied to promote personal and professional growth and development (Myers \& McCaulley, 1985), the SII (consisting of 313 items) provides a person's career interests, which would be useful in counseling athletes in making a career transition (Wylleman et al., 1999). The counseling sessions based on the MBTI and SII report scores provided individuals with the opportunity to express how committed to the sport role they were at that point in time. If their commitment suggested identity foreclosure, a differentiation was made between situational and psychological foreclosure in subsequent parts of the intervention (Petitpas, 1998). Rapport building, effective listening, and empathic understanding were used during this part of the intervention to allow participants to express their emotions and reactions associated with their career termination (Petitpas, Giges, \& Danish, 1999).

Following the assessment of life events, the intervention focused on helping the individuals identify skills that they developed in sport that could be transferred to other areas of their lives (Mayocchi \& Hanrahan, 2000). This was achieved by drawing upon the MBTI and SII reports to help mobilize existing resources and identifying transferable skills. Goal setting was used to also identify new skills as well as develop future plans. This was done as a means of empowerment, as 
it helped the participants encounter their retirement constructively (Danish et al., 1995).

The third and final aspect of the intervention focused on the development of life skills that can augment the person's ability to cope with their career termination and other future events. Opportunities were provided for the skills identified as transferable, as well as new skills, to be practiced during intervention sessions. Feedback, support, and follow-up were provided to enhance personal competence (Danish et al., 1995).

In this study, the intervention was delivered by the author on a one-on-one basis in office sessions lasting approximately 50 minutes. None of the participants had been involved in a one-on-one psychological intervention previously. The average number of intervention sessions was $3.2(\mathrm{SD}=1.4)$. The control group was offered the intervention at the conclusion of the study, but none of these participants took up this offer.

\section{Data Analysis}

A paired-samples t-test was employed to determine whether the two groups of participants were significantly different at pre-test. Post-intervention treatment group differences, as well as within-group differences over time, were tested using analysis of variance (ANOVA) with Bonferroni corrections.

\section{Results}

\section{BALANCE Scale}

A paired-samples t-test was conducted on the BALANCE Scale scores (Intervention Group, $\mathrm{M}=68.7, \mathrm{SD}=3.7$; Control Group, $\mathrm{M}=69.8, \mathrm{SD}=4.0$ ), and this revealed that both groups did not significantly differ from one another in terms of career transition adjustment difficulties $(\mathrm{p}=.21)$.

\section{Post-Intervention Treatment Group Differences}

Significant post-intervention treatment group differences in favor of the life development intervention were identified for the Situation $(p<.01)$, Self $(p<.001)$, Support $(p<.01)$, and Coping Strategy $(p<.001)$ subscales of the TQS (see Table 1). Within-group significant differences over time were also achieved for the intervention group for the Situation $(p<.001)$, Self $(p<.001)$, Support $(p<.01)$, and Coping Strategy $(p<.001)$ subscales.

\section{Discussion}

The topic of helping athletes upon career termination has grown tremendously, and sport psychologists are often the ones who supply psychological services to retired athletes (Lavallee \& Andersen, 2000). There have, however, been few investigations testing the effectiveness of specific interventions when working with this population (Wylleman et al., 2004). The purpose of this investigation was to assess the efficacy of a life development intervention on career transition adjustment in recently retired professional athletes. Results indicated that a life development intervention can significantly assist elite athletes who experience career termination adjustment difficulties. The particular strength of this intervention is supported 
Table 1 Mean Pre-Test and Post-Test Scores for Coping With Transitions Scales

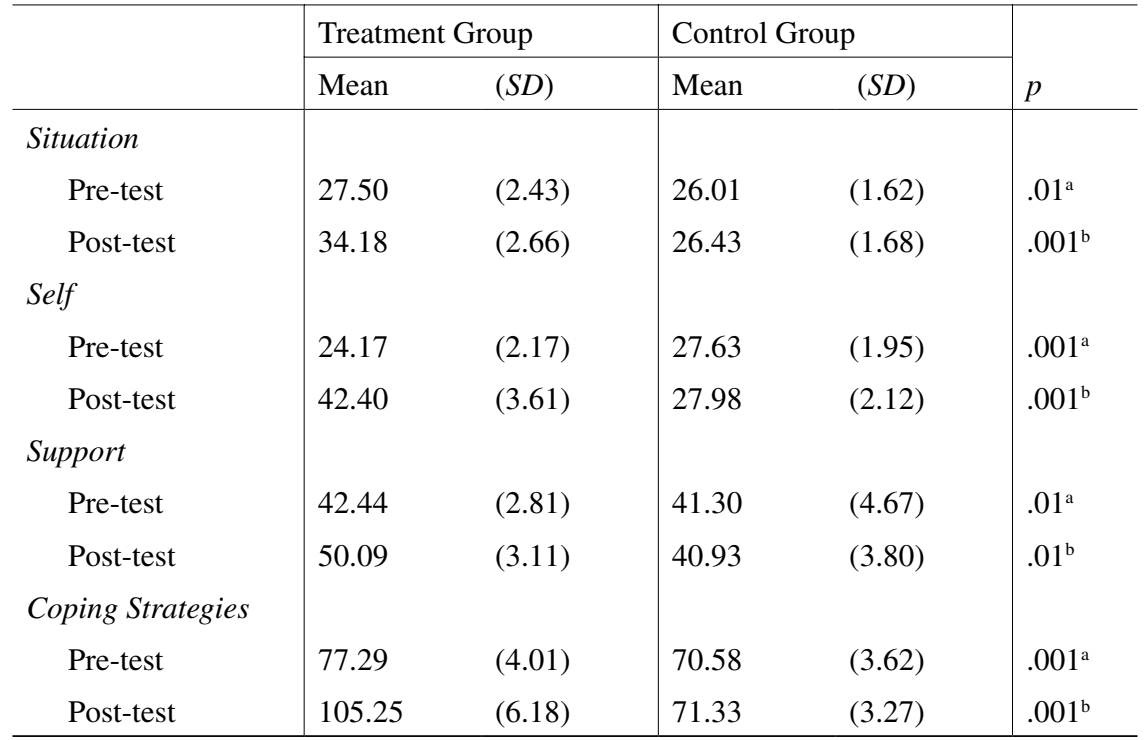

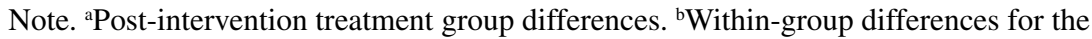
intervention group.

when the relatively short amount of time (an average of 3.2 sessions) required to produce significant effects is considered.

At pre-test, both the post-intervention group and control group were found to have had similar adjustment experiences with regard to their sports career termination as a result of their single, pre-intervention score on the BALANCE Scale. Interestingly, both groups in this study experienced considerable career termination adjustment difficulties on average (Lavallee \& Wylleman, 1999; Lavallee, Golby, $\&$ Lavallee, 2000). The results of the post-intervention treatment group differences subsequently revealed that the intervention group scored significantly higher on the Situation, Self, Support, and Coping Strategy subscales of the TCQ. The mean total scores across all four subscales for both groups at pre-test could be classified as "Moderate" in relation to published norms (Schlossberg, 1993; Schlossberg et al., 1995), suggesting further similarities between the groups in terms of their resources immediately following their career termination. The mean total scores across the four subscales at follow-up for the control group also remained in the Moderate classification.

When compared with the pre-test scores, the intervention group was found to have significant within-group differences across the four TCQ subscales at the four-month follow-up. Furthermore, the post-intervention classification of the mean total scores for the Situation, Self, and Coping Strategies subscales was found to be "Strong" in relation to Schlossberg's norms (Schlossberg, 1993; Schlossberg et al., 1995). These results could be attributed to specific elements of the life development intervention employed in this study. The initial assessment of life events by means 
of the MBTI and SII, for example, may have assisted individuals in the treatment group in developing a better overall understanding of themselves. Broadening the athlete's social identity and role repertoire while maintaining or enhancing feelings of self-confidence and self-worth has been suggested in the literature as a way to assist athletes in transition (Pearson \& Petitpas, 1990). This aspect of the intervention may also have helped these individuals view their situation with regard to their career termination in a more positive way. The transfer of skills from one domain to another, as well as the teaching of new skills to cope with their career termination, were also likely to have had a significant impact on the intervention group's confidence in their ability to cope with their retirement.

Although the post-intervention classification for the Support subscale remained in the Moderate classification, it was significantly higher within the intervention group and was bordering on the Strong classification. This is an interesting finding, because the life development intervention used in this study could not change the support networks on the retired athletes. It is speculated that the intervention assisted these individuals in developing a better understanding of how to use their existing support networks. It is also potentially an important area for future research, as previous authors have advocated the vital importance of social support during the career transition process (Webb et al., 1998).

Further research is also needed on whether performance excellence in elite sport occurs at the expense of the development in personal excellence, and how this impacts the career transition process. Baillie (1993) has stated that the unique issues associated with retirement from sport exist because of the intensity of involvement and commitment of identity that athletes often make to achieve success in their sports (p. 408). Outside of sport, Gardner (1993) has described how talented individuals often become embedded in some kind of deal, arrangement, or "Faustian bargain" executed as a means of ensuring the preservation of their talent. Gardner describes the Faust legend as the best-known example of the widely held belief that talented individuals are special by virtue of their gift and that in order to sustain this gift, they must adhere to some kind of arrangement that requires them to sacrifice the development of excellence in other life domains. Miller and Kerr (2002) have recently proposed an athlete-centered model that encourages the development of life skills during the athlete's career to promote personal excellence and also prevent career transition adjustment difficulties. While these authors acknowledge that it is rare in the elite sport environment for athletes to have formal mechanisms to evaluate their life skills, they propose that sport psychology consultants can facilitate such life skills training. Gould, Collins, Lauer, and Chung (2002) have also recently demonstrated that coaches can assist in the development of life skills among athletes during their career. Given the recent documented evidence on the resistance of active athletes to plan for their post-sporting careers (Gorely et al., 2001; North \& Lavallee, 2004), it is suggested that research also continue to be directed at the development of post-retirement interventions for athletes. The significant results of the present study, which focused on the development of life skills after the athletes had retired, suggests that the individuals possessed the life skills to some extent prior to their retirement and may have develop these further through a targeted intervention.

Research on providing psychological support to athletes in transition is not only scant but highly descriptive in nature. Analyses have consisted mainly of profiling the extent to which athletes have used (or not used) career transition 
program services as well as the components they found to be most (or least) helpful (e.g., Gorely et al., 2001; North \& Lavallee, 2004). These descriptive studies need to be complemented with a stronger evidence base that includes information about the impact of specific psychological interventions on postretirement adjustment.

Given that sports career termination is one of the most significant and potentially traumatic experiences for athletes (Murphy, 1995), further research is also needed on the efficacy of behavioral, cognitive, emotional, and social interventions for athletes in transition. Stress inoculation therapy (Meichenbaum, 1977), emotional expression (Yalom, 1980), and cognitive restructuring (Beck, 1979) have continuously been recommended in the literature as techniques to facilitate career termination adjustment among elite athletes. No research has been published on the use of these interventions in sport settings, however.

The present investigation has several limitations. The life development intervention protocol employed in this study varied in terms of the intervention duration, making exact replication of the study difficult. In addition, the study sample was relatively small, and there was a long recruitment period (approximately 3 years). Potential selection bias is another limitation, although the intervention group did include only athletes that were self-referred. Future researchers may wish to examine any differences between referred and self-referred retired athletes with regard to psychological adjustment difficulties.

In conclusion, the life development intervention employed in this investigation was shown to be effective in significantly assisting elite athletes in their career transition adjustment. Once an initial assessment of life events was conducted, resources were mobilized and then skills were identified and developed to help cope with the career transition. As Petitpas (1998) has previously stated, it is helpful to consider the timing of the intervention in determining what strategies to use. Traditionally, life development interventions occurring before an event use enhancement strategies, those occurring during an event employ supportive strategies, and interventions occurring after an event use counseling strategies (Danish et al., 1993, 1995). Both supportive and counseling strategies were used in this intervention, as the transition out of sport following career termination was seen a transitional process rather than as an isolated event (Kerr \& Dacyshyn, 2000).

\section{References}

Andersen, M.B., Van Raalte, J.L., \& Brewer, B.W. (2001). Sport psychology service delivery: Staying ethical while keeping loose. Professional psychology: Research and Practice, 32, 12-18.

Baillie, P.H.F. (1993). Understanding retirement from sports: Therapeutic ideas for helping athletes in transition. The Counseling Psychologist, 21, 399-410.

Baillie, P.H.F., \& Danish, S.J. (1992). Understanding the career transition of athletes. The Sport Psychologist, 6, 77-98.

Beck, A.T. (1979). Cognitive therapy and emotional disorders. New York: New American Library.

Consulting Psychologists Press. (1985). Strong Interest Inventory. Palo Alto, CA: Author.

Curtis, J., \& Ennis, R. (1988). Negative consequences of leaving competitive sport? Comparison findings for former elite-level hockey players. Sociology of Sport Journal, 5, 87-106. 
Danish, S.J., Petitpas, A.J., \& Hale, B.D. (1993). Life development intervention for athletes: Life skills through sports. The Counseling Psychologist, 21, 352-385.

Danish, S.J., Petitpas, A.J., \& Hale, B.D. (1995). Psychological interventions: A life developmental model. In S. Murphy (Ed.), Sport psychology interventions (pp. 19-38). Champaign, IL: Human Kinetics.

FEPSAC (2004). Activities: Position statements. Retrieved 23 August from http:// www.fepsac.org/

Gardner, H. (1993). Creating minds: The anatomy of creativity seen through the lives of Freud, Einstein, Picasso, Stravinsky, Eliot, Graham, and Gandhi. New York: Basic Books.

Gordon, S. (1995). Career transitions in competitive sport. In T. Morris \& J. Summers (Eds.), Sport psychology: Theory, applications and issues (pp. 474-501). Brisbane: Jacaranda Wiley.

Gorely, T., Lavallee, D., Bruce, D., Teale, B., \& Lavallee, R.M. (2001). An evaluation of the Athlete Career and Education Program. Athletic Academic Journal, 15, 11-21.

Gould, D. (2002). Sport psychology in the new millennium: The psychology of athletic excellence and beyond. Journal of Applied Sport Psychology, 14, 137-139.

Gould, D., Collins, K., Lauer, L., \& Chung, Y. (2002). Examining strategies outstanding high school football coaches use to develop life skills and character in their players: Final project report. University of North Carolina at Greensboro: Author

Grove, J.R., Lavallee, D., \& Gordon, S. (1997). Coping with retirement from sport: The influence of athletic identity. Journal of Applied Sport Psychology, 9, 191-203.

Grove, J.R., Lavallee, D., Gordon, S., \& Harvey, J.H. (1998). Account-making: A model for understanding and resolving distressful reactions to retirement from sport. The Sport Psychologist, 12, 52-67.

Kerr, G., \& Dacyshyn, A. (2000). The retirement experiences of female elite gymnasts. Journal of Applied Sport Psychology, 12, 115-133.

Kleiber, D., Greendorfer, S., Blinde, E., \& Sandall, D. (1987). Quality of exit from university sports and subsequent life satisfaction. Sociology of Sport Journal, 4, 28-36.

Lavallee, D., \& Andersen, M. (2000). Leaving sport: Easing career transitions. In M.B. Andersen (Ed.), Doing sport psychology (pp. 249-261). Champaign, IL: Human Kinetics.

Lavallee, D., Golby, J., \& Lavallee, R.M. (2002). Coping with retirement from professional sport. In I.M. Cockerill (Ed.), Solutions in sport psychology (pp. 184-197). London: Brooks/Cole.

Lavallee, D., Grove, J.R., \& Gordon, S. (1997). The causes of career termination from sport and their relationship to post-retirement adjustment among elite-amateur athletes in Australia. The Australian Psychologist, 32, 131-135.

Lavallee, D., \& Wylleman, P. (1999). Toward an instrument to assess the quality of adjustment to career transitions in sport: The British Athlete Lifestyle Assessment Needs in Career and Education (BALANCE) Scale. In V. Hosek, P. Tilinger, \& L. Bilek (Eds.), Psychology of sport and exercise: Enhancing the quality of life (pp. 322-324). Prague, Czech: Charles University.

Lavallee, D., Wylleman, P., \& Sinclair, D.A. (2000). Career transitions in sport: An annotated bibliography. In D. Lavallee \& P. Wylleman, (Eds.), Career transitions in sport: International perspectives (pp. 207-258). Morgantown, WV: Fitness Information Technology.

Mayocchi, L. \& Hanrahan, S.J. (2000). Transferable skills for career change. In D. Lavallee \& P. Wylleman (Eds.), Career transitions in sport: International perspectives (pp. 95-110). Morgantown, WV: Fitness Information Technology.

Meichenbaum, D. (1977). Cognitive-behavior modification. New York: Plenum. 
Miller, P.S., \& Kerr, G.A. (2002). Conceptualizing excellence: Past, present, and future. Journal of Applied Sport Psychology, 14, 140-153.

Murphy, S.M. (1995). Transitions in competitive sport: Maximizing individual potential. In S.M. Murphy (Ed.), Sport psychology interventions (pp. 331-346). Champaign, IL: Human Kinetics.

Murphy, G.M., Petitpas, A.J., \& Brewer, B.W. (1996). Identity foreclosure, athletic identity, and career maturity in intercollegiate athletes. The Sport Psychologist, 10, 239-246.

Myers, I.B., \& McCaulley, M.H. (1985) Manual: A guide to the development and use of the Myers-Briggs Type Indicator. Palo Alto, CA: Consulting Psychologists Press.

North, J., \& Lavallee, D. (2004). An investigation of potential users of career transition services in the United Kingdom. Psychology of Sport and Exercise, 5, 77-84.

Pearson, R., \& Petitpas, A. (1990). Transitions of athletes: Developmental and preventive perspectives. Journal of Counseling and Development, 69, 7-10.

Petitpas, A.J. (1998). Counseling interventions in applied sport psychology. In J.L. Van Raalte \& B.W. Brewer (Eds.), Exploring sport and exercise psychology (pp. 189-204). Washington, DC: American Psychological Association.

Petitpas, A.J., Giges, B., \& Danish, S.J. (1999). The sport psychologist-athlete relationship: Implications for training. The Sport Psychologist, 13, 344-357.

Schlossberg, N. (1993). Transition Coping Questionnaire. Minneapolis, MN: Personnel Decisions.

Schlossberg, N.K., Waters, E.B., \& Goodman, J. (1995). Counseling adults in transition: Linking practice with theory. New York: Springer.

Sinclair, D. A., \& Orlick, T. (1993). Positive transitions from high-performance sport. The Sport Psychologist, 7, 138-150.

Swain, D.A. (1991). Withdrawal from sport and Schlossberg's model of transitions. Sociology of Sport Journal, 8, 152-160.

Taylor, J., \& Ogilvie, B.C. (2001). Career transitions among athletes: Is there life after sports? In J.M. Williams (Ed.) Applied sport psychology: Personal growth to peak performance ( $4^{\text {th }}$ ed.; pp. 480-496). Mountain View, CA: Mayfield.

Webb, W.M., Nasco, S.A., Riley, S., \& Headrick, B. (1998). Athlete identity and reactions to retirement from sports. Journal of Sport Behavior, 21, 338-362.

World Health Organization (1996). Life skills education: Planning for research. Geneva: Author.

Wylleman, P., Alfermann, D., \& Lavallee, D. (2004). Career transitions in sport: European perspectives. Psychology of Sport and Exercise, 5, 7-20.

Wylleman, P., Lavallee, D., \& Aflermann, D. (Eds.) (1999). Career transitions in competitive sports. Biel, Switzerland: European Federation of Sport Psychology Monograph Series.

Yalom, I.D. (1980). Existential psychotherapy. New York: Harper Collins.

Manuscript submitted: May 24, 2004

Revision received: September 21, 2004 